\title{
ANALYSIS OF PEDESTRIAN BEHAVIOR IN THE CITY OF PILA
}

Piotr Gorzelańczyk ${ }^{1, *}$, Jakub Bazela ${ }^{1}$, Tomáš Kalina², Martin Jurkovič²

${ }^{1}$ Stanislaw Staszic University of Applied Sciences in Pila, Pila, Poland

${ }^{2}$ Department of Water Transport, Faculty of Operation and Economics of Transport and Communications, University of Zilina, Zilina, Slovak Republic

*E-mail of corresponding author: piotr.gorzelanczyk@puss.pila.pl

\section{Resume}

Every year, many people lose their health and/or lives on Polish roads. One of the reasons for this is behavior of pedestrians at pedestrian crossings, which affects the road safety. The aim of the article was to conduct experimental research, the idea of which was to study the behavior of pedestrians at pedestrian crossings in the city of Pila, the results of which can be applied to Poland. During the research, the behavior of pedestrians and the impact on the probability of a road accident were analyzed. Undoubtedly, the prevailing epidemic, during which people are in many respects limited, had an impact on the results obtained, therefore the number of people at the analyzed crossings may have decreased. The conducted research confirmed the Police statistical data that the most dangerous crossings for pedestrians are those without traffic lights.

\section{Article info}

Received 12 August 2021

Accepted 3 November 2021

Online 19 January 2022

\section{Keywords:}

safety

pedestrians

pedestrian crossing

road traffic

\section{Introduction}

Every year many road accidents happen on Polish roads. Many people lose their lives or health. The reason, among others, is inadequate behavior of pedestrians at. Despite the construction of new, safer roads and pedestrian crossings, the number of road accidents continues to increase and about three thousand accident participants die each year. On average, fortyone thousand people are injured each year. The main causes of accidents are speed maladjustment to the prevailing road conditions or regulations, driving under the influence of alcohol and random events, as well as pedestrians who are not checking whether the crossing would be safe before actually entering the crossings (Table 1) [1].

One can study pedestrian behavior in several ways. The first is the direct observation of the road situation without the knowledge of the person observed in natural conditions, arranged observations that take place in natural conditions and in laboratory conditions. People participating in the pedestrian behavior research are aware of these observations, some situations are triggered on purpose. Arranged observations contain elements of danger, usually they are recorded in the form of a film, analysis of pedestrian crash data to determine information about pedestrian behavior before and after the accident [2]. Pedestrian behavior depends on many factors, such as street design, as well as behavior of other pedestrians etc.

An example of pedestrian misbehavior is hesitation. There are times when a pedestrian is in front of a pedestrian crossing, stops in front of it, informing the driver that he may pass and then the pedestrian suddenly changes his mind and invades the crossing. Crossing the road in inappropriate places is also irresponsible behavior, especially since these are usually unlit places. Outside built-up areas, there are situations in which pedestrians do not know which side of the road they should be walking on. At the intersection with traffic lights, a situation occurs in which a pedestrian, despite the red light on, behaves irresponsibly and without hesitation enters the crossing. Going further in search of dangerous pedestrian behavior, one comes to a road situation in which part of the pedestrian crossing is occupied by vehicles parked along the road. In such places, pedestrians are not always clearly visible because they are partially or completely obscured by a vehicle parked along the road. The pedestrian is already at the crossing, but is not visible to drivers. People often forget about that and do not make sure whether they can continue to cross, [3-4].

The problem of pedestrian crossings and their safety was discussed in many publications. For example, the information related to the lighting of pedestrian crossings, the work takes into account the technical equipment of vehicles that affect the pedestrian safety 
[5]. Detailed behavior of pedestrians, influencing the occurrence of a road accident with their participation, is described in [3]. The problem of the road safety including pedestrians was considered in publicaions [6-9]. Security is a human need [10]. The improvement of road safety is affected by many elements related not only to the promotion of proper behaviour among drivers [11-13], but also to the proper organisation of traffic, the appropriate technical condition of roads and vehicles [14-18]. The most commonly used models in security are: control, convergence, deviation and management models, derived from the general theory and latent conditions, pathological, vector-protection, energy flow and energy improvement models energy flow and energy enhancement models derived from epidemiological and energetic theories [19].

\section{Analysis of the road incidents involving pedestrians}

According to the police data, in 2013-2019 there were 232,170 accidents, 21,125 people died, 279,450 people were injured, there were 2,801,195 collisions. For comparison, in the analyzed period, there were 529 accidents in the Pila poviat, 88 people died, 683 were injured and 8,564 collisions occurred [1]. The data is presented in e Table 1.

When analyzing the data, it can be seen that the number of accidents was the highest in 2013 and the lowest in 2019. Over the years, however, the number of collisions has increased. In 2013, there were 355,943 collisions and in 2019 - 455,454. The lowest number of collisions was recorded in $2014-348,028$. The most

Table 1 Number of road incidents in Poland and the Pila poviat in 2013-2019 [1]

\begin{tabular}{|c|c|c|c|c|c|c|c|c|c|c|c|c|}
\hline \multirow{3}{*}{ Year } & \multicolumn{4}{|c|}{ Poland } & \multicolumn{4}{|c|}{ Pila Poviat } & \multicolumn{4}{|c|}{$\begin{array}{l}\text { Percentage share of the Pila county in } \\
\text { events in Poland, \% }\end{array}$} \\
\hline & \multicolumn{4}{|c|}{ Number of } & \multicolumn{4}{|c|}{ Number of } & \multicolumn{4}{|c|}{ Number of } \\
\hline & accidents & killed & injured & collisions & accidents & killed & injured & collisions & accidents & killed & injured & collisions \\
\hline 2013 & 35847 & 3357 & 44059 & 355943 & 116 & 14 & 168 & 1110 & 0.32 & 0.42 & 0.38 & 0.31 \\
\hline 2014 & 34970 & 3202 & 42545 & 348028 & 106 & 14 & 132 & 1017 & 0.30 & 0.44 & 0.31 & 0.29 \\
\hline 2015 & 32967 & 2938 & 39778 & 362265 & 75 & 8 & 95 & 1114 & 0.23 & 0.27 & 0.24 & 0.31 \\
\hline 2016 & 33664 & 3026 & 40766 & 406622 & 85 & 19 & 122 & 1235 & 0.25 & 0.63 & 0.30 & 0.30 \\
\hline 2017 & 32760 & 2831 & 39466 & 436469 & 56 & 12 & 66 & 1337 & 0.17 & 0.42 & 0.17 & 0.31 \\
\hline 2018 & 31674 & 2862 & 37359 & 436414 & 47 & 12 & 48 & 1335 & 0.15 & 0.42 & 0.13 & 0.31 \\
\hline 2019 & 30288 & 2909 & 35477 & 455454 & 44 & 9 & 52 & 1416 & 0.15 & 0.31 & 0.15 & 0.31 \\
\hline Sum & 232170 & 21125 & 279450 & 2801195 & 529 & 88 & 683 & 8564 & --- & --- & --- & --- \\
\hline Average & 33167 & 3018 & 39921 & 400171 & 76 & 13 & 98 & 1223 & --- & --- & --- & --- \\
\hline
\end{tabular}

Table 2 Number of road incidents in Poland and the Pila poviat with participation of pedestrians in 2013-2019 [1]

\begin{tabular}{|c|c|c|c|c|c|c|c|c|c|}
\hline \multirow{3}{*}{ Year } & \multicolumn{3}{|c|}{ Poland } & \multicolumn{3}{|c|}{ Pila Poviat } & \multicolumn{3}{|c|}{$\begin{array}{l}\text { Percentage share of the Pila } \\
\text { county in events in Poland, \% }\end{array}$} \\
\hline & \multicolumn{3}{|c|}{ Number of } & \multicolumn{3}{|c|}{ Number of } & \multicolumn{3}{|c|}{ Number of } \\
\hline & accidents & killed & injured & accidents & killed & injured & accidents & killed & injured \\
\hline 2013 & 9489 & 1147 & 9004 & 16 & 0 & 8 & 0.17 & 0.00 & 0.09 \\
\hline 2014 & 9106 & 1127 & 8592 & 15 & 0 & 16 & 0.16 & 0.00 & 0.19 \\
\hline 2015 & 8581 & 923 & 8188 & 10 & 0 & 10 & 0.12 & 0.00 & 0.12 \\
\hline 2016 & 8461 & 868 & 7974 & 6 & 0 & 6 & 0.07 & 0.00 & 0.08 \\
\hline 2017 & 8197 & 873 & 7587 & 8 & 0 & 9 & 0.10 & 0.00 & 0.12 \\
\hline 2018 & 7548 & 803 & 6918 & 10 & 1 & 9 & 0.13 & 0.12 & 0.13 \\
\hline 2019 & 7005 & 793 & 6361 & 6 & 1 & 5 & 0.09 & 0.13 & 0.08 \\
\hline Sum & 58387 & 6534 & 54624 & 71 & 2 & 63 & --- & --- & --- \\
\hline Average & 8341 & 933 & 7803 & 10 & 0 & 9 & --- & --- & --- \\
\hline
\end{tabular}




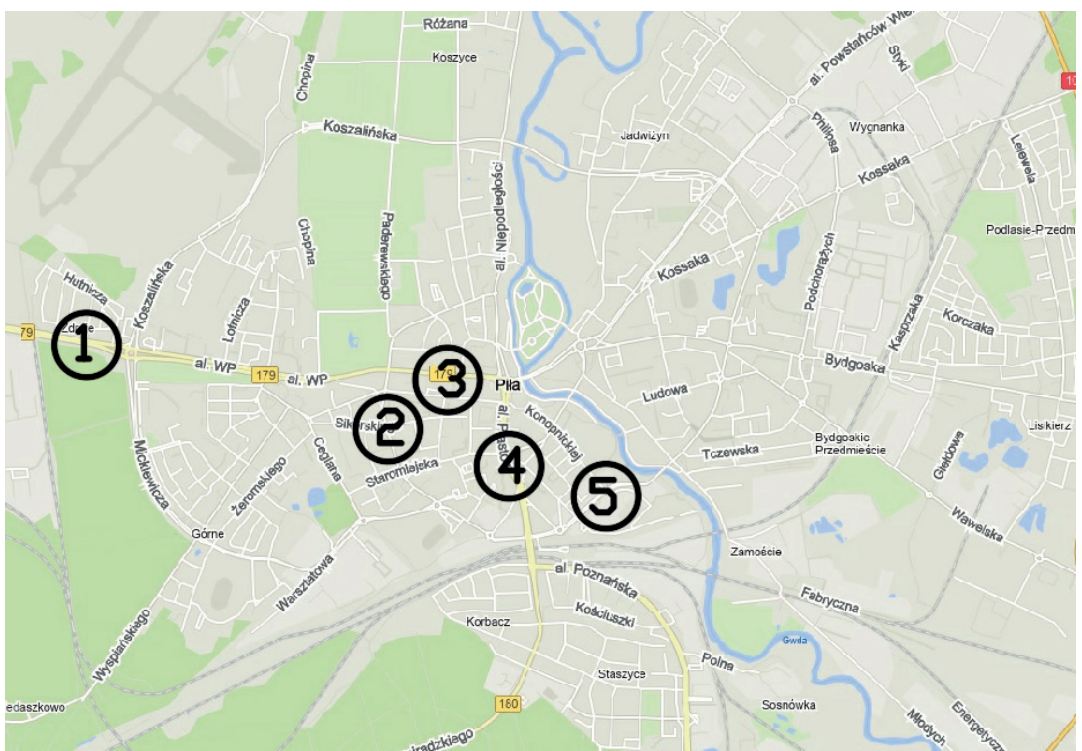

Figure 1 Locations of the tested crossings [21]

injured persons were recorded in 2013 - 44,059 and the least in 2019 - 35,477 people. The year 2013 was also the year of the highest number of deaths - 3,357 people and the lowest number of deaths was in $2017-2,831$. It can also be seen that in the analyzed period, the number of injured exceeded the number of accidents. Based on the above data, it can be concluded that a similar relationship exists in the case of the Pila poviat.

According to the police data, in 2013-2019 there were 58,587 accidents with pedestrians, in which 6,534 people died and 54,624 were injured. For comparison, in the analyzed period, 71 accidents occurred in the Pila poviat, 2 people died and 63 people were injured. The data are presented in Table 2 .

Analyzing the data, it can be noticed that the number of pedestrian accidents was the highest in 2013 and has decreased over the years, reaching a minimum in 2019. The number of injured as well as the number of accidents was the highest in 2013 - 9004 and the lowest in 2019 - 6361. Agagin, 2013 was also the year of the highest number of deaths - 1147, which decreased over the years. In turn, in the Pila poviat, the number of accidents involving pedestrians is decreasing year by year and the number of fatalities in 2018 and 2019 increased by $100 \%$ compared to $2013-2017$. On the other hand, the number of injured was lowest in 2019 and highest in 2014.

According to the Police Headquarters statistics, in 2019 the most accidents involving pedestrians took place in places designated for crossing the road, i.e. at pedestrian crossings $(11.4 \%)$, then at intersections $(6$ $\%)$, sidewalks $(1 \%)$, pedestrian roads and berms $(0.2 \%$ of all road accidents in 2019) [1]. The most common causes of pedestrian accidents are: hitting the road directly in front of a moving vehicle, crossing the road at an unacceptable place, entering the road from the rear of the vehicle, obstacles and driving on a road with a red light $[1,3,10]$.

\section{Research}

\subsection{Purpose and scope of the study}

The aim of the research was to investigate the behavior of pedestrians in front of and at the pedestrian crossing in the city of Pila. Particular attention was paid to how pedestrians react to approaching a pedestrian crossing. Additionally, during the research, road traffic measurements were made around the tested pedestrian crossings.

The research was carried out on four pedestrian crossings in the analyzed city. Two of them, with the highest number of incidents, were selected based on the statistical data from the last three years, provided by the Pila County Police Headquarters [1]. The most dangerous in terms of the wounded and killed are the intersections at Aleja Wojska Polskiego 1 (provincial road 179) and at ul. Okrzei. The next two intersections were selected based on the amount of road traffic taking place there [20]. The first one is also located at Aleja Wojska Polskiego 2 (provincial road 179), but much closer to the city center. The next intersection is at Aleja Piastow Street, it is the city center (provincial road 180). Additionally, a pedestrian crossing in the "VIVO" gallery was examined. This passage is on the bike path. The tested crossings were marked by numbers from 1 to 4 . The pedestrian crossing on the bicycle path was marked by number 5 .

\subsection{Methodology of the conducted research}

During the experimental research, the behavior of pedestrians was analyzed, attention was paid to how they behave when approaching the intersection, before the crossing itself and when crossing the road from one side to the other. Particular attention has been paid to 
whether the pedestrian makes sure that the vehicle is not approaching the crossing. Another element was to pay attention to how many people use a mobile phone while staying within the crossing and at the crossing itself. As a result one can conclude that pedestrians do not pay attention to what is important, i.e. their safety. Another element that was noticed during the research was forcing the right of way by a pedestrian who, despite seeing an approaching vehicle, decided to invade the road anyway. The last element examined was a situation in which a pedestrian decides to walk without making sure that no vehicle is approaching. Additionally, on each crossing, the sum of vehicles passing through this crossing was counted. Each of the analyzed passages was tested on six different days at different times of the day in the following hours: 10-11, 14-15, 17-18.

\section{Results}

The first test was the pedestrian crossing at Aleja Wojska Polskiego 1 (Figure 1 - item 1) located at the provincial road No. 179. At this pedestrian crossing, the ratio of the number of vehicles to pedestrians was 99:1. That depends on the location of the crossing. It is located further away from the city center, on the exit route from the city. Total of 176 people took part in the pedestrian crossing study and the number of vehicles in the study was 16193 . In this case, there was the same number of male and female pedestrians.

Figure 2 presents data on the number of pedestrians at particular times of the day. By far the largest number of pedestrians at the crossing was on February 16, 2020, December 28, 2020, March 5, 2021 and March 8, 2021. This was recorded at 14 and 1 This may be because

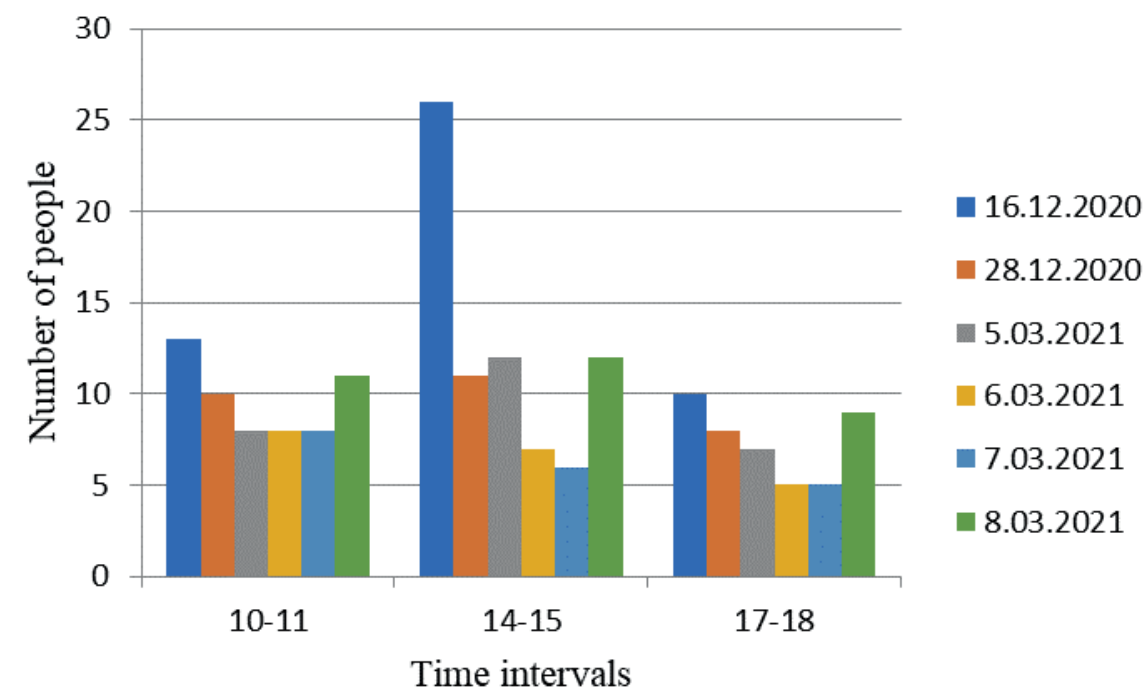

Figure 2 Number of people in particular time periods at crossing \#1



Figure 3 The number of people in each age category at crossing \#1 
Table 3 Test results at the intersection at Aleja Wojska Polskiego1 (crossing \#1)

\begin{tabular}{cccccccccccccc}
\hline Sex & \multicolumn{4}{c}{ Men } & \multicolumn{1}{c}{ Women } & Average \\
\hline Age category & $<20$ & $20-40$ & $40-60$ & $>60$ & Average & $<20$ & $20-40$ & $40-60$ & $>60$ & Average & \\
\hline Confirmation [\%] & 77.78 & 91.67 & 84.09 & 90.91 & 86.11 & 83.33 & 89.66 & 73.17 & 100.00 & 86.54 & 86.33 \\
Failure [\%] & 22.22 & 4.17 & 11.36 & 9.09 & 11.71 & 16.67 & 6.90 & 19.51 & 0.00 & 10.77 & 11.24 \\
Priority enforcement [\%] & 0.00 & 4.17 & 0.00 & 0.00 & 1.04 & 0.00 & 3.45 & 7.32 & 0.00 & 2.69 & 1.87 \\
Taking care of the phone [\%] & 0.00 & 0.00 & 4.55 & 0.00 & 1.14 & 0.00 & 0.00 & 0.00 & 0.00 & 0.00 & 0.57 \\
\hline
\end{tabular}

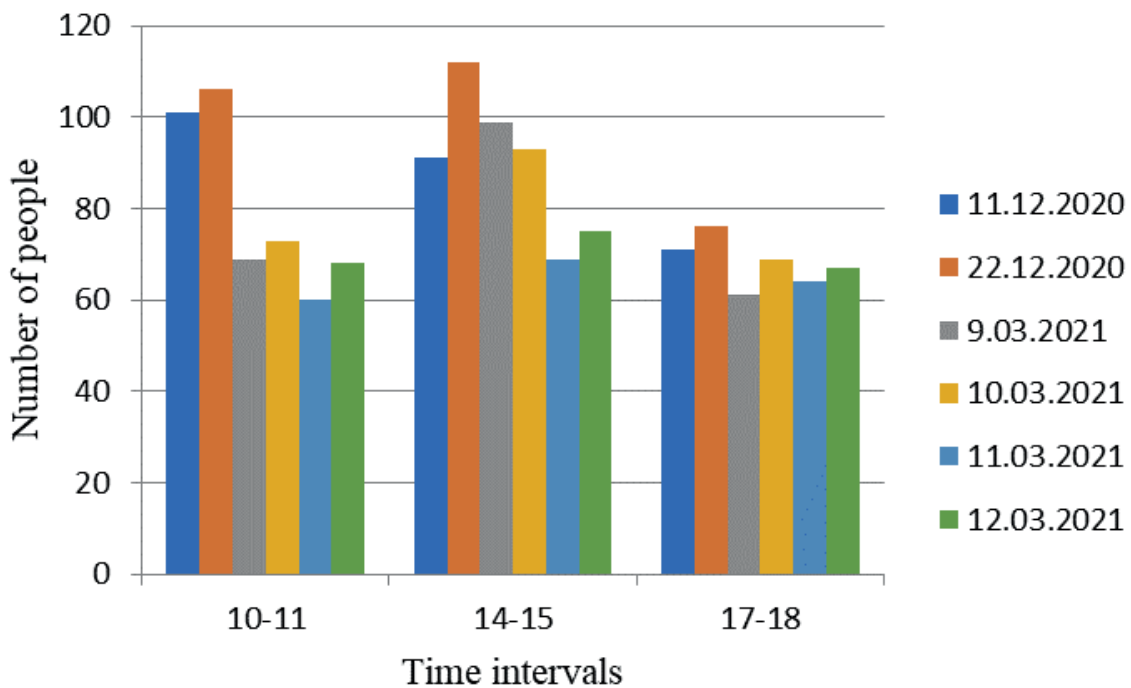

Figure 4 Number of people in particular time intervals at crossing \#2

people go home after work during these hours. In turn, on March 6, 2021 and March 7, 2021, the most people were recorded in the period 10-11.

Then, Figure 3 presents data on the age assumed by the researcher in the study participants. Most of the people were 40-60 years of age, then in the range of $20-40$ and then $<20$ and $>60$ years of age. The age of the respondents was organoleptically approved at the time of preservation. This is due to the presence of nearby jobs.

Table 3 shows the results of the tests carried out at the intersection at Aleja Wojska Polskiego1. The obtained values were divided into age categories for women and men. Self-assessment accounted for $86.33 \%$ of all respondents at this intersection. The highest percentage when crossing the road after checking was found in women over $60(100 \%)$ and the lowest in the 40-60 age group (73.17\%) and also in women. When comparing the performance of men and women at the crossing, women were more alert.

Taking into account another of the examined elements, i.e. entering a pedestrian crossing, it was $11.24 \%$ of the respondents who crossed without the prior checking. The highest percentage was reported for men aged up to 20 (22.22 \%). Comparing this to women over the age of 60 , who did not tried to cross without making sure, the value is very high and in the future it might have dire consequences. In addition in the case of the study of the number of unknown people, women obtained a lower percentage. This state was $11.24 \%$ and in men $11.71 \%$.

The next analyzed fragment is the fragment marked by number 2 on the overview map (Figure 1). Pasage at Stefana Okrzei Street is located near the city center. During the pedestrian crossing research, 1.424 people were tested, during this time 8.735 vehicles passed through the pedestrian crossing. In this case, the vehicle to pedestrian ratio was $86: 14$. This result may be influenced by the fact that Stefana Okrzei Street is not a voivodeship road. It is a lower capacity road. The number of women and men among the respondents was similar.

The number of pedestrians in the time intervals is shown in Figure 4. The results in the individual hourly intervals are similar. The highest number of people was observed in the time interval 14-15, with the exception of December 11, 2020. On that day, the highest number of people was recorded in the 10-11 range. This result may be influenced by the fact that people leave work between 14 and 15 and go back to their homes. The fewest people passed between 17 and 18., except on March 11, 2021, in the case of that day, the least people passed in the 10-11 time interval.

Among the respondents, the greatest number of people in each age category was in the 20-40 age group. In turn, the smallest number of people differed in the 


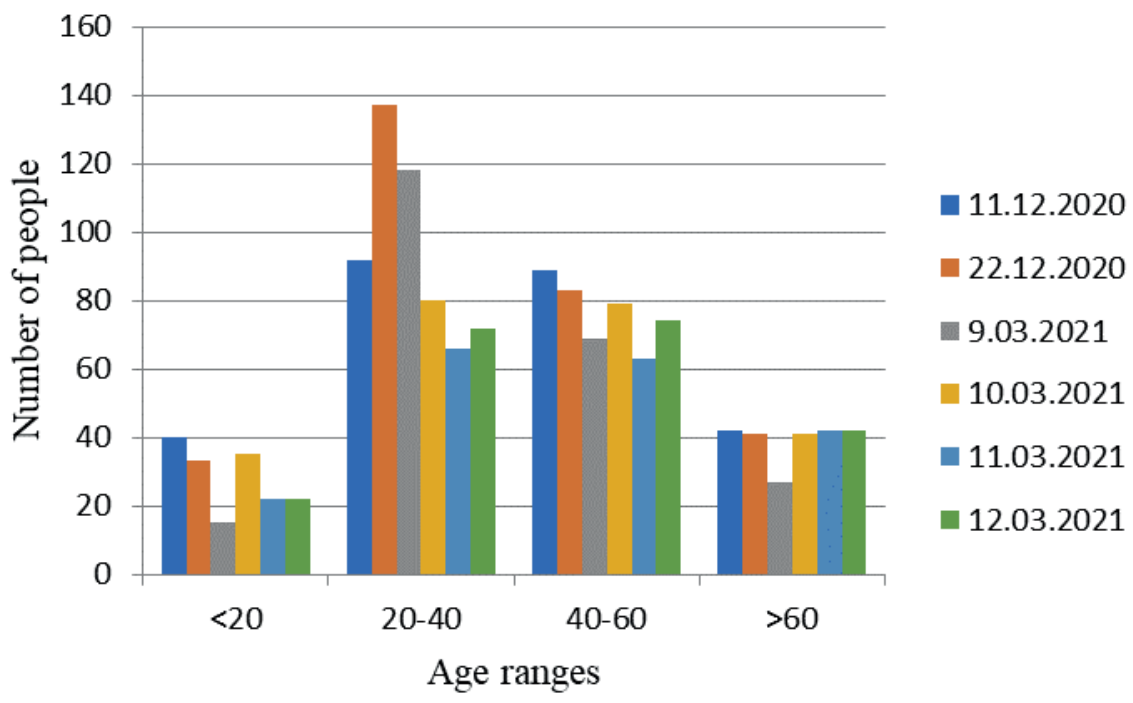

Figure 5 Number of people in each age category at crossing \#2

Table 4 Test results at the crossing at Stefana Okrzei Street (crossing \#2)

\begin{tabular}{cccccccccccc}
\hline Sex & \multicolumn{3}{c}{ Men } & \multicolumn{1}{c}{ Women } & Average \\
\hline Age category & $<20$ & $20-40$ & $40-60$ & $>60$ & Average & $<20$ & $20-40$ & $40-60$ & $>60$ & Average & 90.12 \\
\hline Confirmation [\%] & 85.56 & 89.45 & 92.74 & 88.79 & 89.13 & 88.31 & 93.24 & 92.24 & 90.60 & 91.10 & 6.96 \\
$\quad$ Failure [\%] & 10.00 & 7.64 & 5.98 & 7.76 & 7.84 & 7.79 & 5.07 & 4.57 & 6.84 & 6.07 & 1.62 \\
$\begin{array}{c}\text { Priority enforcement } \\
\text { [\%] }\end{array}$ & 1.11 & 1.09 & 1.28 & 3.45 & 1.73 & 1.30 & 0.34 & 1.83 & 2.56 & 1.51 & 1.33 \\
$\begin{array}{c}\text { Taking care of the } \\
\text { phone [\%] }\end{array}$ & 3.33 & 1.82 & 0.00 & 0.00 & 1.29 & 2.60 & 1.35 & 1.37 & 0.00 & 1.31 \\
\hline
\end{tabular}

age category under 20 and similarly in the age group over 60 . The data is presented in Figure 5.

Analyzing the results of the research presented in Table 4 and referring to all the respondents, the percentage of pedestrians who checked themselves before entering the road was $90.12 \%$. The lowest value was achieved in the age category up to 20 years among men, where it was $85.56 \%$. The highest was recorded for women in the 20-40 age group, i.ee $93.24 \%$. Comparing women and men, women $(91.10 \%$ vs men - $89.13 \%$,) obtained a higher percentage of passes after the prior checking.

People who did not make sure before entering the pedestrian crossing, but entered it without paying attention to the traffic situation, accounted for $6.96 \%$ of all respondents. The lowest percentage was recorded in the group of women aged 40-60 (4.57\%). The highest was obtained in the case of men up to 20 years old and amounted to $10 \%$. After testing this behavior, women $(6.07 \%)$ obtained a lower value than men $(7.84 \%)$.

The next pedestrian crossing examined was also located at Aleja Wojska Polskiego 2 (Figure 1 - item 3 ), but this location is much closer to the city center compared to the previous analyzed crossing on this street. In the case of this pedestrian crossing, 1,361 pedestrians were tested. In the case of this crossing, the number of pedestrians is $7 \%$ and vehicles are $93 \%$.
The location of the pedestrian crossing undoubtedly influenced such results. It is located much closer to the city center in the vicinity of apartment blocks. As in the previously analyzed places, the number of women and men was very similar.

The largest number of people using the examined crossing on each of the studied days was in the hour range from 14 to 15 . The smallest number of people using the pedestrian crossing was in the period of 10-11o'clock, which may result from the fact that during the period the epidemiological status of activities in schools or universities took place only online, so such a situation could lead to a decrease in the number of people crossing the street period during this period. On the other hand, the highest number of pedestrians in the 14-15 period may be due to the fact that many pedestrians come to or from work (Figure 6).

As shown in Figure 7, most people were 40-60 years old, then 20-40 years old, > 60 years old and the least < 20 years old. In each of the age categories, the number of people was similar. In one case, the number of people on one day (March 20, 2021) was much greater than on the other days. The case concerned the age category up to 20 years. The reason may be a day off from distance classes and sunny weather on that day. December 23, 2020 was also a day off, but on that day the weather conditions were much worse than March 20, 2021. 


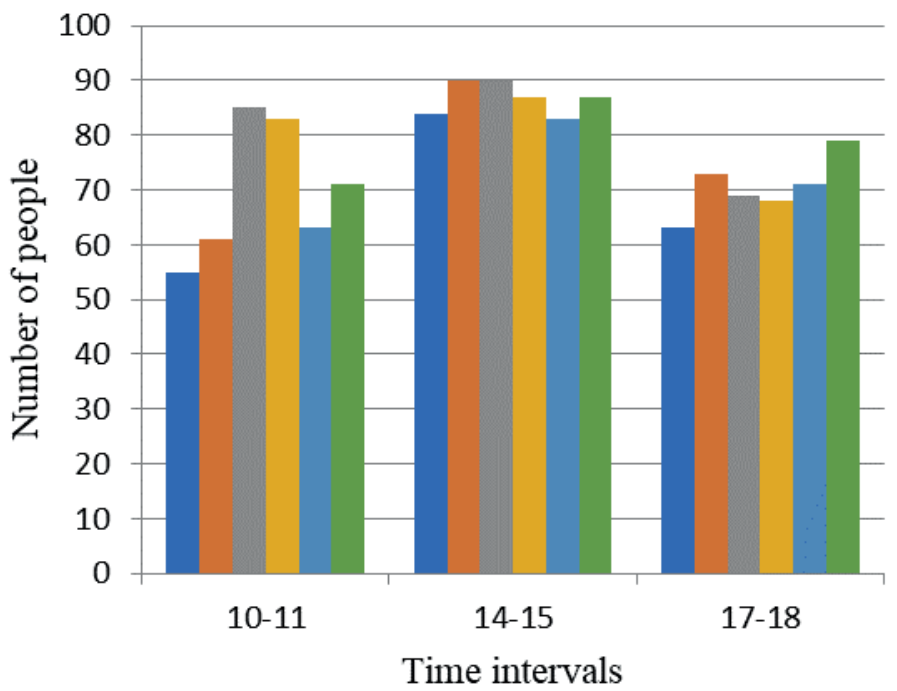

3.12 .2020

- 23.12.2020

17.03.2021

18.03.2021

19.03.2021

$-20.03 .2021$

Figure 6 Number of people in particular time intervals at crossing \#3

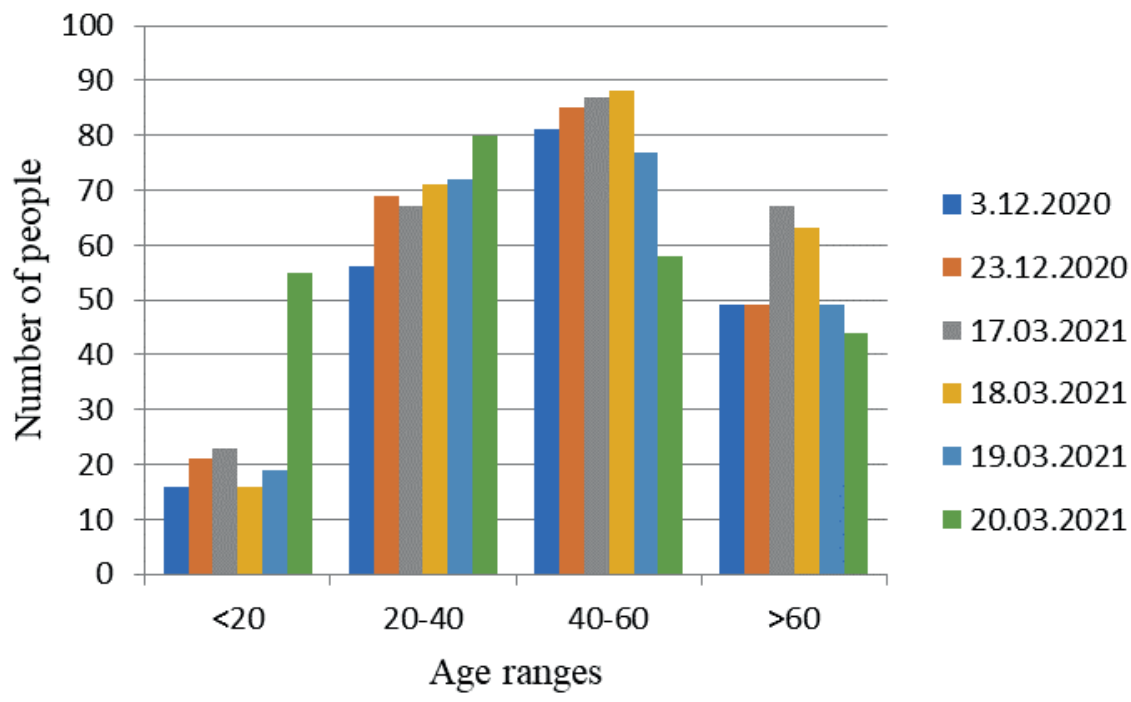

Figure 7 Number of people in each age category at crossing \#3

Table 5 presents data for women and men in different age categories at the analyzed crossing. First, the data on making sure before crossing the road is presented. Out of all the people surveyed, $91.15 \%$ were self-reassurances. The group of men aged over 60 was distinguished by the highest percentage, it amounted to $96.65 \%$. The lowest percentage was recorded for men up to the age of 20 , it was $83.91 \%$. The average percentage of women was $91.52 \%$, which made men worse in this respect and obtained an average of $90.78 \%$.

Then, data on people who did not make sure before entering the pedestrian crossing were presented, which constituted $6.65 \%$ of all surveyed people. Among those who did not check, the largest number was recorded among men in the age category up to $20(10.34 \%)$ and among women in the same age category $(7.94 \%)$. The lowest value was noticed in the case of men aged over 60 , it was $3.35 \%$. The data presented in the table below also shows that men $(6.95 \%)$ more often than women $(6.35 \%)$ decide to intrude on a pedestrian crossing without first making sure.

The pedestrian crossing from Aleja Piastow was further examined. The crossing is located in the city center by the provincial road no. 180. A more precise location of the intersection is shown on the overview map (Figure 1 - no. 4). The total number of people tested at this pedestrian crossing was 1987 people and the number of vehicles passing through this crossing during the study was 18,047 . In this case, the ratio of number of vehicles to number of pedestrians is: 90:10. When broken down into women and men, it can be seen that the number of women (52\%) is greater than that of men (48\%). The difference in favor of women was $4 \%$.

The number of people at the pedestrian crossing at specified intervals and on two different test days is presented in Figure 8. Analyzing, it can be noticed that the number of people on 01/03/2021 was the highest than on the other test days. Most people used the crossing in 
Table 5 The results at the crossing at Aleja Wojska Polskiego2 (crossing \#3)

\begin{tabular}{cccccccccccccc}
\hline Sex & \multicolumn{4}{c}{ Men } & \multicolumn{1}{c}{ Women } & Average \\
\hline Age category & $<20$ & $20-40$ & $40-60$ & $>60$ & Average & $<20$ & $20-40$ & $40-60$ & $>60$ & Average & \\
\hline Confirmation [\%] & 83.91 & 90.50 & 92.06 & 96.65 & 90.78 & 92.06 & 90.70 & 93.87 & 89.44 & 91.52 & 91.15 \\
Failure [\%] & 10.34 & 8.50 & 5.61 & 3.35 & 6.95 & 7.94 & 6.51 & 4.60 & 6.34 & 6.35 & 6.65 \\
Priority enforcement [\%] & 0.00 & 0.00 & 0.93 & 0.00 & 0.23 & 0.00 & 0.47 & 0.38 & 4.23 & 1.27 & 0.75 \\
Taking care of the phone [\%] & 5.75 & 1.00 & 1.40 & 0.00 & 2.04 & 0.00 & 2.33 & 1.15 & 0.00 & 0.87 & 1.45 \\
\hline
\end{tabular}

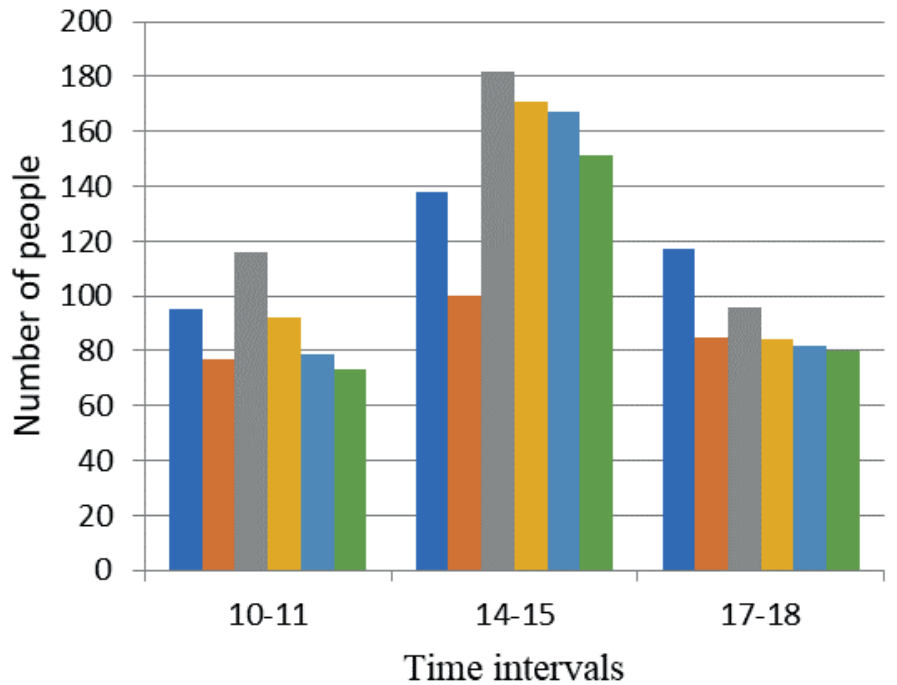

15.12 .2020

- 29.12.2020

1.03.2021

2.03.2021

- 3.03.2021

4.03.2021

Figure 8 Number of people in particular time intervals at crossing \#4

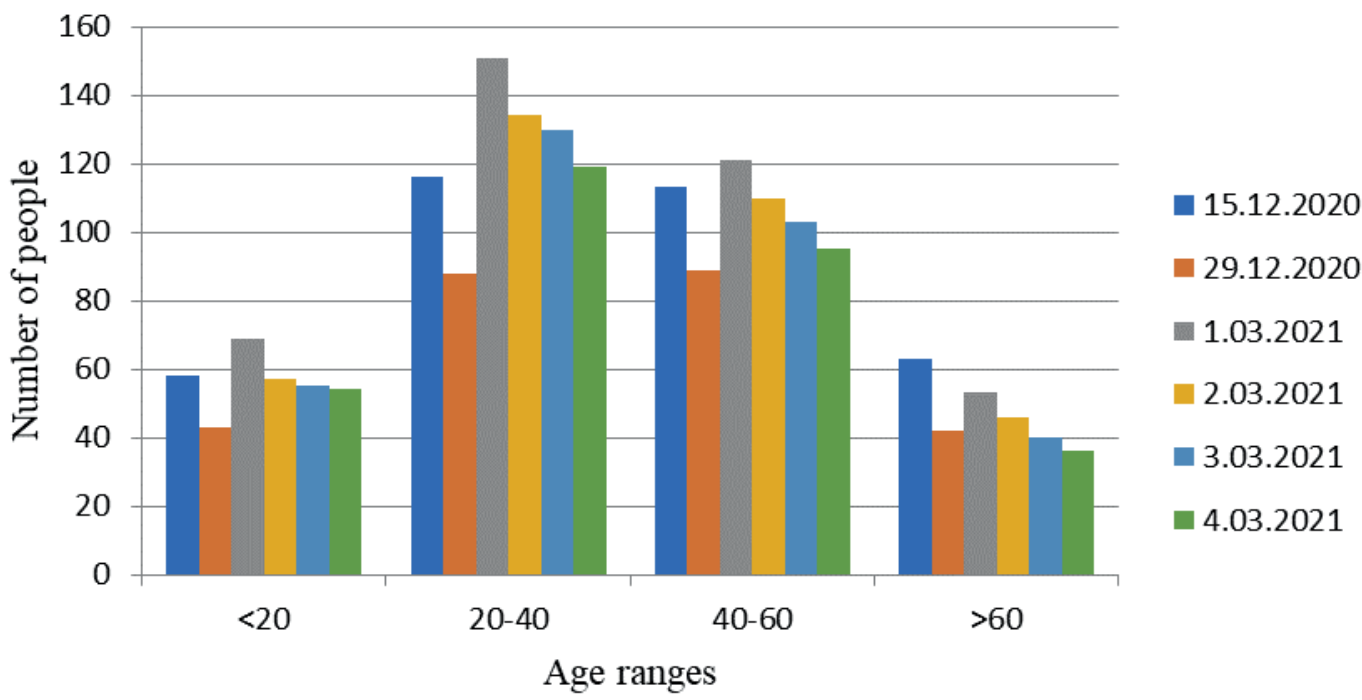

Figure 9 Number of people in each age category at crossing \#4

the period 1415 This situation could be caused by the fact that some people attended or were from work. The smallest number of people was recorded between 10 and 11 o'clock.

The lowest number of people was recorded in the age group under 20 , followed by those over 60 . In the remaining age categories, the number of people was very similar. However, more people were between the ages of 20 and 40 (Figure 9).
Out of all the respondents at this pedestrian crossing, 90.74\% entered the $\mathrm{n}$ crossing after being checked (Table 6). In the age category up to 20 , women enter $94.87 \%$ after checking. The lowest result was recorded in men over 60 years of age. It was $87.94 \%$. Comparing the results of women and men, women obtained a more favorable average, ie $91.85 \%$ in men, the average was $89.63 \%$.

Out of all the respondents, $6.38 \%$ entered the 
Table 6 Test results at the crossing at Aleja Piastow (crossing \#4)

\begin{tabular}{ccccccccccccc}
\hline Sex & \multicolumn{4}{c}{ Men } & \multicolumn{1}{c}{ Women } & Average \\
\hline Age category & $<20$ & $20-40$ & $40-60$ & $>60$ & Average & $<20$ & $20-40$ & $40-60$ & $>60$ & Average & \\
\hline Confirmation [\%] & 90.56 & 88.58 & 91.44 & 87.94 & 89.63 & 94.87 & 91.77 & 90.00 & 90.78 & 91.85 & 90.74 \\
Failure [\%] & 8.33 & 5.25 & 6.16 & 9.93 & 7.42 & 1.92 & 5.33 & 5.59 & 8.51 & 5.34 & 6.38 \\
Priority enforcement [\%] & 1.11 & 2.78 & 2.05 & 2.13 & 2.02 & 1.28 & 1.69 & 2.65 & 0.71 & 1.58 & 1.80 \\
Taking care of the phone [\%] & 0.00 & 3.40 & 0.34 & 0.00 & 0.93 & 1.92 & 1.21 & 1.76 & 0.00 & 1.22 & 1.08 \\
\hline
\end{tabular}

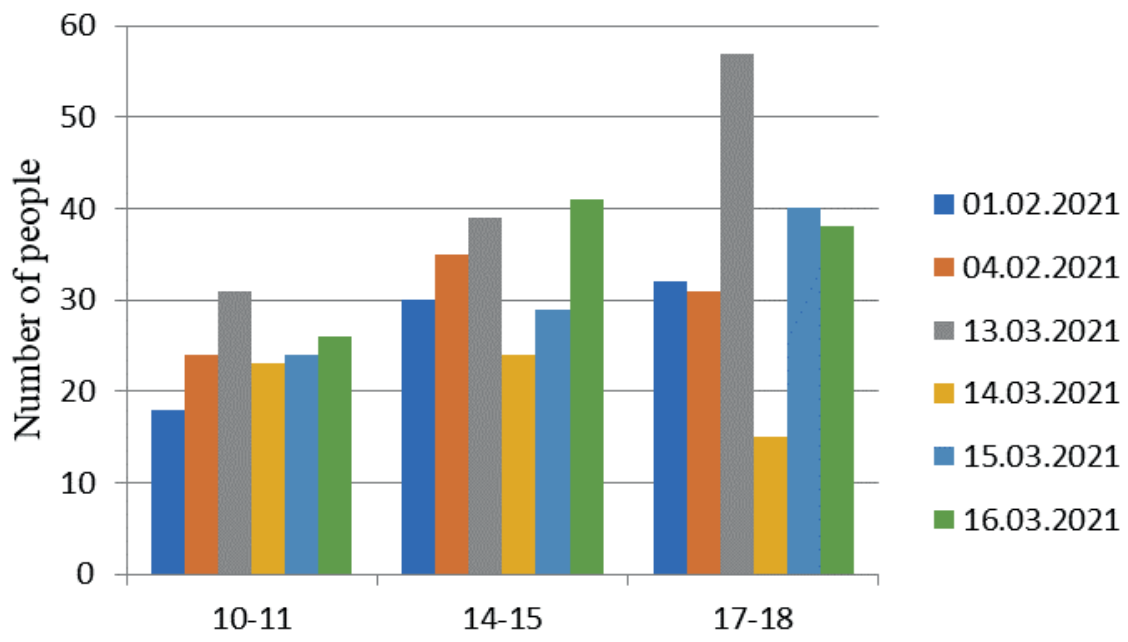

Time intervals

Figure 10 Number of people in each age category at crossing \#5

crossing without first knowing that a vehicle was approaching. The highest percentage was achieved by men over $60(9.93 \%)$. In turn, the lowest result was obtained by the group of women up to 20 years of age, ie $1.92 \%$. The average for women was $5.34 \%$ and for men $7.42 \%$.

Among the respondents there were also people who forced priority $(1.80 \%)$. The highest percentage of reports after forced priority was in the 20-40 age group among men, it was $2.78 \%$. In this behavior, the age category over 60 for women was the best, where the result was $0.71 \%$. Comparing women and men, the lower average was obtained by women, ie $1.58 \%$ and men by $2.02 \%$.

In the case of this pedestrian crossing, the youngest age group of women used a telephone while crossing the road $(1.92 \%)$. In several age categories, no person dealing with the telephone was recorded. Among men, these are the following age categories: $<20,>60$ years, for women: $>60$ years. Referring to the whole, $1.08 \%$ of the respondents used the telephone during the crossing. It is $1.22 \%$ for women and $0.93 \%$ for men.

The last of the pedestrian crossings tested was on the bicycle path marked by number 5 in Figure 1. During the study, 557 people were tested and 165 cyclists traveled along the bicycle path. In this case, the pedestrian-to-cyclist ratio was 77:23. Such a difference was undoubtedly influ due to the prevailing pandemic.
The vast majority of the respondents are women (63\%), 26\% more than men (37\%). The location of the passage next to the shopping center may also affect the obtained result.

Most people used this crossing between 17 and 18 o'clock On the other hand, the lowest number of people was between 10 and 11 (Figure 10). The smallest number of people in this hourly window may be due to the fact that the shopping center opens at 10.

Figure 11 presents data on the number of people in each age group at the examined crossing on six different days. The smallest number of people was recorded in age categories over 60 and then up to 20. Most people were in the $20-40$ and $40-60$ age group.

When conducting the research on a pedestrian crossing on a bicycle path, the same cases of behavior were investigated as at intersections located on the road. Of all those surveyed, $65.53 \%$ walked through the crossing after making sure there was no oncoming cyclist. As far as age categories are concerned, the group of men aged 20 obtained the lowest result (57.14 \%). The highest result was recorded in the age category over 60 for men $(74.19 \%)$. Women obtained a higher percentage than men, amounting to $66.24 \%$ to $64.82 \%$ (Table 7).

The rest of the respondents were people who were not careful when entering the pedestrian crossing. The highest value was recorded for women aged over 60 and amounted to $36.36 \%$ and for women aged $20-40,24.22 \%$. 


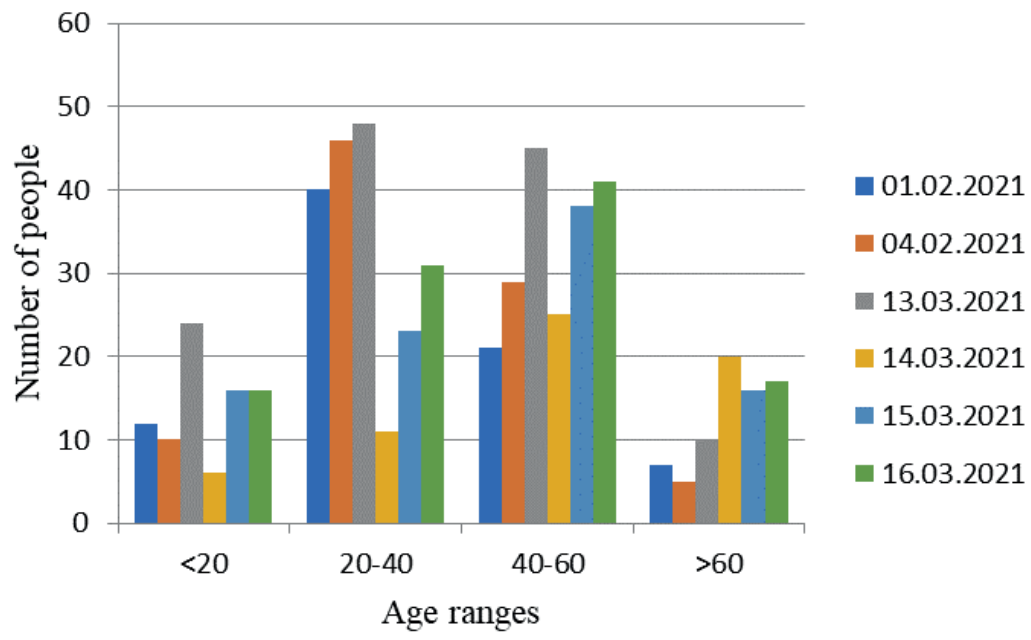

Figure 11 Number of people in each age category at crossing \#5

Table 7 The results on the sidewalk in the "VIVO" gallery in percent (crossing \#5)

\begin{tabular}{cccccccccccccc}
\hline Sex & \multicolumn{1}{c}{ Men } & \multicolumn{1}{c}{ Women } & Average \\
\hline Age category & $<20$ & $20-40$ & $40-60$ & $>60$ & Average & $<20$ & $20-40$ & $40-60$ & $>60$ & Average & \\
\hline Confirmation [\%] & 57.14 & 66.20 & 61.76 & 74.19 & 64.82 & 59.18 & 72.66 & 69.47 & 63.64 & 66.24 & 65.53 \\
Failure [\%] & 34.29 & 32.39 & 33.82 & 25.81 & 31.58 & 28.57 & 24.22 & 25.19 & 36.36 & 28.59 & 30.08 \\
Priority enforcement [\%] & 0.00 & 0.00 & 0.00 & 0.00 & 0.00 & 0.00 & 0.00 & 0.00 & 0.00 & 0.00 & 0.00 \\
Taking care of the phone [\%] & 8.57 & 1.41 & 4.41 & 0.00 & 3.60 & 12.24 & 3.13 & 5.34 & 0.00 & 5.18 & 4.39 \\
\hline
\end{tabular}

When comparing men and women, women were rated as better. Their percentage was $28.59 \%$. This result is lower than that of men by more than $2.5 \%$. For all the respondents at this intersection, $30.08 \%$ were unsure.

Further research has been carried out on how many people are forced to prioritize cyclists. Such behavior was not reported in any case. This result could have been influenced by the weather during the tests - the bicycle path on which the tests were conducted was not in the best condition, i.e. it was covered with snow, which meant that the number of cyclists had significantly decreased than if the tests had been carried out in better weather conditions.

The last behavior tested was to determine how many people deal with a mobile phone while walking. People dealing with the phone while crossing the pedestrian crossing accounted for $4.39 \%$ of the total number of people surveyed there. The highest value was obtained by women aged $<20(12.24 \%)$. There were also age groups where this behavior was not reported. In the case of women and men, this is the age group over $60(0$ $\%)$. Comparing women and men, men obtained a lower percentage $-3.6 \%$, while for women $5.18 \%$.

\section{Research conclusions}

Comparing all the tested crossings to ensure that pedestrians before entering the road obtained the best result, pedestrians using the intersection in $\mathrm{Al}$. Wojska
Polskiego2 (Figure 1 - point 3). Over $91 \%$ of respondents at this crossing made sure before entering the crossing. Another result is $90.74 \%$ of people watching over the pedestrian crossing in Aleja Piastow. At the pedestrian crossing at Stefana Okrzei Street, the percentage of people who were checking the safety was $90.12 \%$. Then there was a pedestrian crossing at Aleja Wojska Polskiego 1, on which $86.33 \%$ of all the pedestrians tested at this intersection made sure of safe crossing before actually entering. The worst result was obtained by pedestrians using the crossing located on the bicycle path by the "VIVO" gallery. This result was $65.53 \%$ (Table 8).

The greatest number of pedestrians who did not make sure before entering the pedestrian crossing was recorded at the intersection located on the bicycle path. Of all the surveyed pedestrians, as many as $30.08 \%$ of people were not sure if a cyclist was approaching. Pedestrians staying at the crossing in Aleja Wojska Polskiego 1 achieved the second high result $-11.24 \%$. The second place was taken by the pedestrian crossing at Stefana Okrzei Street. Pedestrians using this crossing obtained the percentage of $6.96 \%$. The result of $6.65 \%$ was recorded for pedestrians staying at the crossing in Aleja Wojska Polskiego 2. The lowest and, at the same time, the most favorable for safety result was recorded for pedestrians using the crossing in Aleja Piastow. It was $6.38 \%$.

Another behavior noticed was forcing pedestrians to take precedence. Such behavior was not noted in any of 
Table 8 Comparison of the results on each of the tested crossings

\begin{tabular}{ccccccc}
\hline Zebra crossing & $\begin{array}{c}\text { Aleja Wojska } \\
\text { Polskieg01 }\end{array}$ & $\begin{array}{c}\text { Aleja Wojska } \\
\text { Polskiego2 }\end{array}$ & $\begin{array}{c}\text { Stefana } \\
\text { Okrzei }\end{array}$ & Alei Piastow & $\begin{array}{c}\text { next to the } \\
\text { "VIVO" } \\
\text { gallery. }\end{array}$ & Average \\
\hline Confirmation [\%] & 86.33 & 91.15 & 90.12 & 90.74 & 65.53 & 84.77 \\
Failure [\%] & 11.24 & 6.65 & 6.96 & 6.38 & 30.08 & 12.26 \\
Priority enforcement [\%] & 1.87 & 0.75 & 1.62 & 1.80 & 0.00 & 1.21 \\
Taking care of the phone [\%] & 0.57 & 1.45 & 1.31 & 1.08 & 4.39 & 1.76 \\
\hline
\end{tabular}

Table 9 Comparison of results by the analyzed road type

\begin{tabular}{cccc}
\hline Zebra crossing & National Road & Local road & Bike path \\
\hline Confirmation [\%] & 89.41 & 90.12 & 65.53 \\
Failure [\%] & 8.09 & 6.96 & 30.08 \\
Priority enforcement [\%] & 1.47 & 1.62 & 0.00 \\
Taking care of the phone [\%] & 1.03 & 1.31 & 4.39 \\
\hline
\end{tabular}

Table 10 Comparison of results on each of the tested crossings broken down to age categories

\begin{tabular}{cccccccccccc}
\hline Sex & \multicolumn{4}{c}{ Men } & \multicolumn{4}{c}{ Women } \\
\hline Age category & $<20$ & $20-40$ & $40-60$ & $>60$ & Average & $<20$ & $20-40$ & $40-60$ & $>60$ & Average \\
\hline Confirmation [\%] & 78.99 & 85.28 & 84.42 & 87.70 & 84.10 & 83.55 & 87.61 & 83.75 & 86.89 & 85.45 \\
Failure [\%] & 17.04 & 11.59 & 12.59 & 11.19 & 13.10 & 12.58 & 9.61 & 11.89 & 11.61 & 11.42 \\
Priority enforcement [\%] & 0.44 & 1.61 & 0.85 & 1.12 & 1.01 & 0.52 & 1.19 & 2.44 & 1.50 & 1.41 \\
Taking care of the phone [\%] & 3.53 & 1.53 & 2.14 & 0.00 & 1.80 & 3.35 & 1.60 & 1.92 & 0.00 & 1.72 \\
\hline
\end{tabular}

the surveyed pedestrians $(0 \%)$ at the pedestrian crossing in the "VIVO" gallery. This happened because when the pedestrian approached the crossing, there was no cyclist nearby. The weather had an impact on the traffic on the cycle path. The next result was obtained by pedestrians using the crossing in Aleja Wojska Polskiego2, with a percentage result of $0.75 \%$. The second result was recorded for pedestrians using the pedestrian crossing at Stefana Okrzei Street. The recorded result was $1.62 \%$. At the intersection located at Aleja Piastow, a percentage of $1.8 \%$ was recorded among all those surveyed at this intersection. The highest percentage of this behavior was recorded at the intersection at Aleja Wojska Polskiego2 - 1.87\%.

The last pedestrian behavior surveyed was to check how many pedestrians were using the mobile phone while crossing. The highest percentage was recorded among pedestrians using the crossing on the bicycle path, it was $4.39 \%$. In the case of crossing in Aleja Wojska Polskiego 2, pedestrians obtained $1.45 \%$; at the crossing at Stefan Okrzei it was $1.31 \%$., while the result of $1.08 \%$ was recorded at the intersection in Aleja Piastow. The lowest result and at the same time the most advantageous in terms of safety, was recorded at the intersection at Aleja Wojska Polskiego 1 - 0.57\%.

Based on the obtained results, it can be concluded that the most dangerous pedestrian crossing in Pila is located at Aleja Wojska Polskiego1, which is also reflected in reality. According to the data of the Pila County Police Headquarters [1], a large number of incidents involving pedestrians took place at this intersection. Pedestrians examined at this intersection obtained the least favorable results in terms of safety. Very often their behavior was improper, they did not focus on the crossing, which led to a situation where they entered the crossing without making sure about safe crossing.

Comparing the results of the national and local road surveys it can be seen that they are similar in terms of the criteria analysed: confirmation, failure, priority enforcement and taking care of the phone. However, fewer people were chacking the safety when crossing the cycle path and more people used the phone when crossing it (Table 9).

Taking into account the data in Table 10, women are more confident in crossing than men. The situation is similar in the case of people over 60 years of age. The most dangerous category at pedestrian crossings are young people up to 20 years of age who are entering the crossing without caution and use the mobile phone very often when crossing. Police campaigns promoting the safe crossing of pedestrian crossings should be targeted at this group of people.

\section{Summary}

In conclusions, authors can state that their research was conducted objectively and that they obtained the reliable results. The behavior of pedestrians 
at a pedestrian crossings has been observed. The research was carried out on the most dangerous pedestrian crossings in the city of Pila and the extent to which pedestrians contributed to a road accident was determined. The prevailing epidemic has undoubtedly influenced the results, due to the fact thta people were limited in many respects, therefore the number of people at crossings may have been lower than in the normal conditions. The conducted research confirmed the statistical data that the most dangerous crossings for pedestrians are those without traffic lights. For that reason, it is justified to continue the Police action for safety at pedestrian crossings. The authors plan to repeat the research once the pandemic is over.

\section{References}

[1] Road accidents in Poland. Statistical report. Police Headquarters (in Polish) [online] [accessed 2021-03-21]. Available from: https://statystyka.policja.pl/

[2] LESKO, M., GUZIK, J. Road traffic control: controllers and systems of traffic control and supervision (in Polish). Gliwice: Publishing House of the Silesian University of Technology, 2020. ISBN 8388000675.

[3] WITKOWSKI, J. Pedestrian in road traffic (in Polish). Warsaw: Publishing House of Communication and Communication, 1978.

[4] LESNIKOWSKA-MATUSIAK, I., DABROWSKA-LORANC, M. Communication education for children and adolescents' didactic manual (in Polish). Warsaw, ITS Publishing House, 2005. ISBN 83-919774-6-3.

[5] GACA, S., SUCHORZEWSKI, W., TRACZ, M. Road traffic engineering. Theory and practice (in Polish). Warsaw: Publishing House of Communication and Communication, 2014. ISBN 978-83-206-1707-8.

[6] WICHER, J. Safety of cars and road traffic (in Polish). Warsaw: Publishing House of Communication and Communication, 2020. ISBN 978-83-206-1835-8.

[7] NAATANEN, R., SUMMALA, H. Behavior of road users and road accidents (in Polish). Warsaw: Publishing house PWN, 1985.

[8] JAMROZA, K., OSKARBSKA, I. Hazards to pedestrian road users. In: Pedestrian protection. Handbook for Pedestrian Traffic Organizers [online]. Warsaw: Ministerstwo Infrastruktury i Rozwoju, Sektretariat Krajowej Rady BRD, 2014. ISBN 978-83-7610-527-7, p. 12-28. Available from: https://doi.org/10.13140/2.1.3172.9447

[9] GORZELANCZYK, P., PYSZEWSKA, D., KALINA, T., JURKOVIC, M. Road safety analysis in the Pila poviat. Scientific Journal of the Silesian University of Technology. Series Transport [online]. 2020, 107, p. 33-52. ISSN 0209-3324, eISSN 2450-1549. Available from: https://doi.org/10.20858/sjsutst.2020.107.3

[10] BABKOV, W. F. Road conditions and traffic safety. Warsaw: Publishing House of Communication and Communication, 1975.

[11] LINKOV, V., TREPACOVA, M., KURECKOVA, V., PAI, C. W. Novice Czech drivers' ability and willingness to offer the first aid after traffic accidents: the positive effect of the firstaid training. Communications - Scientific Letters of the University of Zilina [online]. 2019, 21(2), p. 114-118. ISSN 1335-4205, Eissn 2585-7878. Available from: https://doi.org/10.26552/com.C.2019.2.114-118

[12] TOPOLSEK, D., OJSTERSEK, T. C. Do drivers behave differently when driving a car or riding a motorcycle? European Transport $\backslash$ Trasporti Europei. 2017, 66, 7. ISSN 1825- 3997.

[13] GOLAKIYA, H. D., CHAUHAN, R., DHAMANIYA, A. Evaluating safe distance for pedestrians on urban midblock sections using trajectory plots. European Transport $\backslash$ Trasporti Europei. 2020, 75, 2. ISSN $1825-3997$.

[14] MOHANTY, M., SAMAL, S. R. Role of young drivers in road crashes: a case study in India. European Transport $\backslash$ Trasporti Europei. 2019, 74, 1. ISSN 1825- 3997.

[15] PRENTKOVSKIS, O., PRENTKOVSKIENE, R., LUKOSEVICIENE, O. Investigation of potential deformations developed by elements of transport and pedestrian traffic restricting gates during motor vehicle-gate interaction. Transport. 2007, 22(3), p. 229-235. https://doi.org/10.3846/16484142.2007.9638130

[16] PRENTKOVSKIS, O., SOKOLOVSKIJ, E., BARTULIS, V. Investigating traffic accidents: A collision of two motor vehicles. Transport [online]. 2010, 25(2), p. 105-115. ISSN 1648-4142, eISSN 1648-3480. Available from: https://doi.org/10.3846/transport.2010.14

[17] DELL'ACQUA, G., DE LUCA, M., PRATO, C. G., PRENTKOVSKIS, O., JUNEVICIUS, R. The impact of vehicle movement on exploitation parameters of roads and runways: a short review of the special issue. Transport [online]. 2016, 31(2), p. 127-132. ISSN 1648-4142, eISSN 1648-3480. Available from: https://doi.org/10.3846/1648 4142.2016.1201912

[18] LUKE, R., HEYNS, G. J. Reducing risky driver behaviour through the implementation of a driver risk management system. Journal of Transport and Supply Chain Management [online]. 2014, 8(1), a146. ISSN 2310-8789, eISSN 1995-5235 Available from: https://doi.org/10.4102/jtscm.v8i1.146

[19] JAMROZ, K. Review of road safety theories and models. Journal of KONBiN [online]. 2008, 1(4), p. 89-108. ISBN 1895-8281. Available from: https://doi.org/10.2478/v10040-008-0012-z 
[20] General Traffic Measurement (in Polish) [online] [accessed 2020-04-28]. Available from: https://www.gddkia. gov.pl/pl/1231/generalny-pomiar-ruchu

[21] Maps google [online] [accessed 2020-04-28]. Available from: https://www.google.pl/maps 